\title{
VERDADE EM TRADUÇÃO: UM TESTEMUNHO DA DOR DAS PALAVRAS
}

\section{TRUTH IN TRANSLATION: A TESTIMONY OF THE PAIN OF WORDS}

\section{Viviane Veras*}

\section{RESUMO}

O objetivo da Comissão de Verdade e Reconciliação (CVR), instituída na África do Sul em julho de 1995 e estendendo-se até agosto de 1997, é possibilitar uma reconciliação nacional, evitando o banho de sangue e instaurando a paz civil. Dizer a verdade, a full disclosure, é o que se exige de cada um que pede a anistia. Não se trata, portanto, de uma anistia geral, concedida de forma automática. Uma vez que a comissão sustenta que é possível "fazer coisas com as palavras", busca-se nas narrativas e nos testemunhos de todos os envolvidos uma verdade suficiente para produzir um consenso, o reconhecimento do passado e a assunção dos crimes, em oposição a uma cultura de impunidade. Nesse contexto, minha proposta é pensar a relação entre tradução e testemunho, pensar o intérprete tradutor como testemunha, sublinhando o fato de que a língua da Comissão, o inglês, é uma língua de tradução, não é a língua das vítimas nem dos torturadores.

Palavras-chave: tradução-interpretação; testemunho; comissão verdade reconciliação

\section{ABSTRACT}

The Truth and Reconciliation Commission (TRC) was established in South Africa in July 1995 and worked until August 1997, and its main goal is to provide national reconciliation, thus preventing a bloodbath and establishing civil peace. Each one who asks for amnesty is required to speak the truth in a full disclosure context. Therefore, it's not the case of a global amnesty which is automatically granted. Once the commission insists upon the possibility of "doing things with words", there is, amid the testimonies and narratives, a quest for some truth that would be enough to provide a consensus, to the acknowledgement of the past and to the assumption of the crimes committed. In such context, I propose a reflection on the relation between translation and testimony, as well as on the role played by the interpreter as witness, stressing the fact that the English language, which was adopted in the context of the commission, is a language used for translation purposes and is neither

\footnotetext{
*. UNICAMP, Campinas (SP), Brasil.viveras@gmail.com
} 
the language spoken by the victims nor by the torturers.

Keywords: translation-interpretation; testimony; Ttruth and Reconciliation Comission

A testemunba promete dizer ou manifestar a outrem, seu destinatário, alguma coisa, uma verdade, um sentido que the foi ou que the é de alguma forma presente, a ela mesma como testemunba - unica e insubstituível. Essa singularidade insubstituível liga a questão do testemunbo à do secreto, mas também à questão, indissociável, da morte que ninguém pode nem antecipar nem ver chegar, nem dar nem receber no lugar do outro.

Jacques Derrida ${ }^{1}$

\section{D'AILLEURS, DERRIDA - ENCENAÇÕES}

Sob a direção de Safaa Fathy (1999) ${ }^{2}$, Jacques Derrida entra em cena no anfiteatro da École des Hautes Études en Sciences Sociales e começa a falar. Nessa cena do filme, retoma o seminário anterior, que havia começado pronunciando, sem contexto, uma única palavra: perdão.

Perdão, sim, perdão.

Acabei de dizer "pardon", em francês.

Por enquanto, vocês provavelmente não entenderam nada.

"Perdão"3.

$\mathrm{Na}$ cena que Derrida anuncia para os alunos, os personagens são quatro. São todos bomens, todos de fé cristã e protestante. Todos - Hegel, Mandela, Tutu, Clinton - sabem um pouco sobre o perdão, a anistia, o perjúrio, o arrependimento, a reconciliação, e nós os escutamos testemunbar. Deste ponto em diante,não é mais a palavra pardonque Derrida enuncia. Antes que se abram as cortinas da cena que ele descreve no anfiteatro, escutamos o espectro de Hegel, uma voz vinda dos bastidores, e que traz Das Wort der Versöbnung. Não a palavra reconciliação, mas a palavra de reconciliação, a palavra da reconciliação, a palavra por meio da qual se oferece a reconciliação, estendendo, primeiro, a mão.

1. Cf. referências, 2004c, p.531.

2. Este trabalho se escrevea partir de falas de Jacques Derrida em D’Ailleurs, Derrida, de Safaa Fathy (1999), e de dois seminários do autor sobre o perdão, o testemunho, a tradução, o perjúrio.

O filme está disponível em http://www.jacquesderrida.com.ar/video/videos.htm Acesso em setembro de 2011.

3. Todos os trechos em itálicos são falas de Jacques Derrida no filme citado. Os trechos entre aspas (2004b, p. 541) são registros de seminários sobre o perdão e o perjúrio realizados na EHESS em 1998 e 1999 (as traduções não referenciadas são minhas). 
O que faz Derrida com essa palavra? O texto que lê agora para os ouvintes da École é um seminário sobre o perdão, o perjúrio e a impunidade, que havia apresentado na Cidade do Cabo, na África do Sul ${ }^{4}$, enquanto acompanhava Nelson Mandela nos trabalhos da Comissão de Verdade e Reconciliação (CVR). Em uma nota a esse texto que agora leio, é Mandela quem entra direto na cena da história, no teatro do mundo, e a palavra de reconciliação está escrita no preâmbulo da nova Constituição Sul-Africana, que termina pela invocação [May God protect our people] das "bênçãos do Deus cristão" (2004a,p. 113).

Presidida por Desmond Tutu, a Comissão se institui como dimensão pública de diálogo e reconhecimento e se oferece como instrumento de transição necessário à passagem do regime de apartheid (que vem selar, em 1948, as leis de segregação racial em vigor desde 1909) para a democracia. Se, por um lado, como diz Desmond Tutu, "aqueles que esquecem o passado estão condenados a repeti-lo" (2000, p. 31), e a rememoração pode trazer a paz; por outro lado, é também com Tutu que na cena da verdade se enxerta a interpretação cristã anglicana da reconciliação,a ordem divina que vê "na extraordinária capacidade de perdão" o sinal da afinidade do povo africano com os mandamentos da lei do deus único (p. 47). Para Derrida (2004a), esse selo cristão vai se imprimir não somente nas línguas, mas na tradução da anistia como perdão condicionado ao arrependimento. O exemplo cristão invocado por Tutu (e ao qual Nelson Mandela não se alia) assemelha-se, para Derrida, "a uma violência, sem dúvida a mais bem intencionada do mundo, mas uma violência aculturante, para não dizer colonial, que não se limita a uma questão superficial de retórica, de língua ou de semântica" (2004a, p. 137).

\section{QUANDO TRADUZIR É RECONCILIAR}

A palavra da reconciliação é ato, o "speech act". Pela palavra..., ao falarmos, inicia-se a reconciliaçãa, oferece-se a reconciliação dirigindo-se ao outro, o que quer dizer ao menos que antes dessa palavra bavia a guerra e o sofrimento, o traumatismo, a ferida. [Ainda no anfiteatro, em Paris, Derrida dirige a palavra a seu público]

Instituída na África do Sul em julho de 1995, e estendendo-se (as sessões públicas) até agosto de 1997, a Comissão de Verdade e Reconciliação propõe a criação de uma memória coletiva, de uma história que terá sido escrita ${ }^{5}$, não a ferro e

4. E também, pela última vez, no Brasil, no "Colóquio Internacional Jacques Derrida - Pensar a desconstrução", no teatro Maison de France, Rio de Janeiro, em 16 de agosto de 2004.

5. É nesse tempo do futuro anterior - tão caro a Jacques Lacan e a Jacques Derrida, ambos na trilha de Sigmund Freud - que leio em Gagnebin (2006, p. 39) que "a verdade do passado remete mais a 
fogo, mas nas línguas e pelas línguas de todos aqueles que viveram, sofreram e também sustentaram o apartheid. A busca da verdade sobre os excessos do passado é considerada uma etapa necessária para um processo de reconciliação nacional que evite o banho de sangue, a vingança, e instaure a paz civil. Dizer a verdade, toda a verdade, a full disclosure, é o que se exige de cada um que pede a anistia, que só será dada em casos de graves violações dos direitos humanos durante determinado período do apartheid - de 21 de março de 1960 (massacre de Sharpeville) a 10 de maio de 1994, data da eleição de Mandela, o primeiro presidente democrático do país. Na Comissão, trata-se, portanto, de uma anistia que repudia a amnésia, o esquecimento; uma anistia particular, nem coletiva nem automática, e é preciso demandá-la de acordo com os critérios da Comissão ${ }^{6}$. O risco da injustiça é real e de viés, e "a anistia foi um preço alto", diz a comissária Yasmin Sooka (2004, p. 340). Com relação aos relatos das testemunhas que sobreviveram a perdas, prisões e torturas, reconhece a importância de conhecer todos os detalhes de suas histórias, e chega mesmo a afirmar que "aprendemos muito com as vítimas, tomadas uma a uma em suas dores" (p. 340). Com relação aos pedidos de anistia, contudo, a comissária sublinha que muitos dos políticos que colaboraram com o regime do apartheid tomavam a Comissão como uma caça às bruxas, e o que os levava ao Comitê da Anistia não era o remorso ou o desejo de reconciliação, mas o interesse pessoal.

É essa indistinção entre anistia e perdão que vai se refletir, constata Barbara Cassin (2004a), na complexa partilha entre ética e política. E entre a lei que institui a Comissão e a definição das tarefas que lhe cabem, a filósofa destrinça os fios do que chamou de um "imbróglio jurídico-político-ético-religioso" (p. 38-40). A impertinência da questão, ela insiste, prende-se ao fato de o apartheid ser um crime contra a humanidade e, como tal, não poder ser nem punido nem perdoado. A dificuldade está em separar o legal e a moral: a Comissão lida com a legalidade - que permite a anistia do ato, uma vez que não se anistia o indivíduo (p. 41), e lida com a moralidade - que dá lugar à 'guerra justa', com sua resposta devastadora ${ }^{7}$. Quanto à questão religiosa trazida por Tutu, Cassin lembra que o apartheid era condenado como pecado, como intrinsecamente mal, o que impunha uma valoração moral. Sua

uma ética da ação presente que a uma problemática da adequação (pretensamente científica) entre 'palavras' e 'fatos'." Volto a essa questão mais adiante.

6. Cf. TRC Report, vol1, cap. 1, p. 7 ("Um dos critérios a ser satisfeito antes de a anistia ser concedida era contar toda a verdade"). Disponível em http://www.doj.gov.za/trc (ver referências).

7. Barbara Cassin (p. 40) distingue pontualmente a postura da Comissão em relação à 'guerra justa', sempre de acordo com a Convenção de Genebra, e aquela declarada por George W. Bush em 12 de setembro de 2001. 
proposta - nesse entrançamento entre política e moral - é a de "puxar somente o fio do político" (p. 39).

Para Philippe-Joseph Salazar (2004), é possível ainda uma conversão (metanoia) política do religioso. Entre trechos do relatório da Truth and Reconciliation Comission (1998) e citações de Tutu em "The divine imperative" (1994), o autor chama a atenção para a forma como o arcebispo articula no palco da Comissão as palavras dos apóstolos: "Ele veio para dizer que Deus nos criou para a fellowship, para a koinônia, para a togetherness, sem que sejam destruídas nossa diferença, nossa alteridade cultural. $\mathrm{O}$ apartheid nega e repudia deliberadamente esse ato central de Jesus". A Igreja oficial, que sustenta o regime de apartheid, "lança a comunidade branca para fora da obra de koinônia [...] que ela [a Igreja] reitera em cada sermão e em cada prece, todo domingo" (p. 72).

Em defesa do trabalho da Comissão, nesse fazer coisas com palavras, escuto em Salazar um eco austiniano: ${ }^{8}$ a apelo à filologia, ao Dictionnairedes intraduisibles, organizado por Cassin (2004c) e à retórica. Articulando verdade (trutb) e reconciliação (reconcil-iatio) como 'confiança', encontra o potencial de cura (bealing) na palavra dada, entre o depoimento (account) do criminoso e o relato (storytelling) da vítima (p. 65). O recurso de Desmond Tutu à Bíblia, tomado de início como um deslocamento do discurso jurídico para o religioso, pode ser lido então, segundo Salazar, como um recurso argumentativo que permite tomar distância do procedimento que busca a verdade judiciária (rapport), fazendo da confissão uma verdadeira performance [no sentido de How to do things with words, de Austin(1962-1975)], um ato de proclamação da verdade narrativa, social. É nesse ponto que Salazar vislumbra "uma passagem, uma ponte, entre apartheid e democracia" (2004, p. 71).

\section{HUMAN WRONGS INTO HUMAN RIGHTS ${ }^{9}$ - 0 GRAFFITI ANÔNIMO}

Derrida fala agora à beira-mar, ailleurs, em El Biar... Só há sentido para o perdão $e$ a reconciliação ali onde a ferida deixou uma lembrança... um rastro e, portanto, uma cicatriz para curar, aliviar, pensar...A partir do momento em que se fala, um processo de reconciliação está em funcionamento...

8. Em A plea for excuses, John L. Austin (1961-1970) sugere aos filósofos que se valham, na sua lida com a lei e com a linguagem ordinária, de um bom dicionário (p. 186-7).

9. Essas palavras, escritas em preto e branco e enquadradas por desenhos coloridos, compõem um grafitti pintado no muro da casa de Desmond Tutu, na Cidade do Cabo, e reproduzido na capa da revista Vérité, Réconciliation, Réparation (publicada em 2004). Cassin vai reescrevê-lo, remetendo a John L. Austin, como: How to do things with - constitutional - words. (2004a, p. 14). 
Entre as críticas à Comissão presidida por Tutu, Derrida (2004a, p. 114) ilumina um problema de tradução: "tomar por natural a tradução dos idiomas africanos". A despeito do reconhecimento de onze línguas oficiais ${ }^{10}-$ Ndebele, Xhosa, Shoto, Shoto do Norte, Tswana, Swati, Venda, Tsonga, Zulu, Africâner, Inglês - legitimadas pela nova Constituição, é previsível a dominação do inglês e não são poucos os problemas de tradução. Durante os trabalhos da CVR, a língua de tradução não é a língua das vítimas, não é a língua de parte dos torturadores, não é a língua materna da maioria dos intérpretes das línguas africanas.Annelie Lotriet (2002) fala do desafio enfrentado por esses profissionais e para a grande dificuldade em encontrar intérpretes que falassem línguas africanas e tivessem o inglês como primeira língua - muitas vezes havia problemas com a gramática ou omissões mais ou menos importantes.

Nesse processo testimonial, a tradução é literalmente trans-missão, uma tarefa imprescindível. O intérprete é uma figura em geral apagada em estudos sobre o testemunho. Há poucas pesquisas sobre seu trabalho - se levarmos em conta a vasta bibliografia sobre a tradução $0^{11}$ - e menos ainda estudos que discutam a diferença de o intérprete precisar estar ali, de corpo presente ${ }^{12}$, mesmo que discreto, separado, apartado da cena de que, no entanto, participa. Assim, quando começam os preparativos para os trabalhos da Comissão não há um corpo de tradutores com treinamento formal em interpretação simultânea. Leio no artigo de Lotriet (2002, p. 83) quena África do Sul são poucos os trabalhos sobre esses intérpretes, que antes de 1994 não se dava aos falantes de mais de uma língua qualquer status superior, e que as línguas africanas (não hegemônicas) nunca haviam sido tão ouvidas. Até então somente duas línguas eram oficiais na África do Sul: o inglês e o africâner - não havia, evidentemente, necessidade de intérpretes no Parlamento. Segundo Christine Anthonissen (2008), em casos que iam à Corte não se exigia o treinamento de intérpretes ("notoriamente invisíveis", p. 169) - qualquer pessoa que falasse mais de uma língua era chamada a interpretar, e eram procuradas especialmente em hospitais e clínicas das comunidades. Com base na reforma política (no

10. A Língua de Sinais Africana (South African Sign Language) também é reconhecida como língua oficial na nova Constituição. Sobre os trabalhos desses intérpretes, ver Lotriet (2001).

11. O testemunho é ligado ao intérprete em relação ao "falso testemunho" ou "falsa perícia", em situações que exigem a presença de um tradutor juramentado. Cf artigo Art. 342 do Código Penal Brasileiro: "Fazer afirmação falsa, ou negar ou calar a verdade como testemunha, perito, contador, tradutor ou intérprete em processo judicial, ou administrativo, inquérito policial, ou em juízo arbitral". (Capítulo III - Dos Crimes Contra a Administração da Justiça, grifos acrescentados).

12. Remeto o leitor ao trabalho de Shoshana Felman e Dori Laub (1992), que discutem a presença do/a tradutor/a no filme Shoab, de Claude Lanzmann. 
reconhecimento de 12 línguas oficiais e na determinação de que ninguém pode ser discriminado com base na língua), o texto da Comissão (TRCReport) estipula igual tratamento para todos.

A necessidade de promover os meios para que as vítimas possam falar na língua de sua escolha exige um tratamento também para os intérpretes. Anthonissen (2008, p. 166) descreve o contrato assinado com a Unit for Language Facilitation and Empowerment (ULFE) para recrutar, selecionar e treinar esses profissionais, e chama a atenção para o fato de que, a despeito de ficarem à vista de todos os participantes (uma vez que as cabines, quando existiam, eram envidraçadas), quase não se fazia referência ao papel desses profissionais. Para a autora, um estudo dos relatos de experiências desses intérpretes (algumas das quais estruturam seu próprio trabalho) pode permitir uma reflexão sobre a difícil tarefa de lidar com língua e memória.

Se no Comitê de Anistia a interpretação dos depoimentos e manifestações de advogados expunha o problema do léxico legal, além de nomes de armas que traziam letras e números, no Comité de Violação dos Direitos Humanos as circunstâncias de interpretação eram excepcionais. $O$ intérprete Lebohang Mathibela, em depoimento a Charles Villa-Vicencio (2007), enumera as dificuldades que ele e os demais intérpretes enfrentavam em seu trabalho em ambos os comitês. $\mathrm{O}$ uso de eufemismos pelos que pediam anistia, e repetiam coisas como "eles precisavam ser definitivamente removidos da sociedade", em vez de dizer que foram mortos. O intérprete cita também o problema com as palavras tabu:"em inglês, sexo é sexo, mas experimente traduzir essa palavra para uma língua africana com os anciãos sentados na plateia usando os fones de ouvido" (2007, p. 116). Em uma das experiências analisadas por Anthonissen (2008), encontra-se o caso de um comissário que, percebendo que a testemunha se dirige ao intérprete, interpela-a:

- Não fale com esse homem, fale comigo.

- Não, afirma a testemunha. Não vou falar com você. Ele [o intérprete] está falando merda.

- Mas, senhor, sou somente o intérprete, o que o senhor quer que eu faça? Eu ouço o que o senhor me diz em Sesotho e passo para o comissário... (p. 178).

O capítulo 10 do Volume I do Relatório apresenta as tarefas de cada comitê: Anistia; Violação dos Direitos Humanos; Reparação e Reabilitação. Nesse capítulo ${ }^{13}$ também são indicados os serviços de tradução, a garantia de que as vítimas podem falar em sua língua, a necessidade de um grupo de intérpretes que possa se deslocar com a Comissão itinerante, e os gastos com esse serviço. O volume III traz os relatos das vítimas organizados cronologicamente em quatro períodos, de acordo

13. Disponível em http://www.doj.gov.za/trc 
com o padrão de violação e refletindo a estrutura regional da Comissão. Uma nota, na página 3, determina que as violações graves são assassinatos, torturas e sequestros, ficando as demais reunidas sob o rótulo de "violações associadas". No volume IV a definição de "graves violações" dos Direitos Humanos é contestada por sua cegueira em relação aos abusos sexuais sofridos pelas mulheres (p. 381). As páginas 418 e 419 do volume V trazem o depoimento de Thenjiwe Mtintso, presidente da Comissão Sul-africana da Igualdade de Gênero: "Não podemos limitar os Direitos Humanos ao que está no Ato. A desigualdade, a injustiça de gênero é uma violação dos Direitos Humanos."

\section{INFINITAS CORTINAS COM PALCOS ATRÁS}

Como recomeçar e falar a todos ao mesmo tempo? ... Como esse 'dirigir-se a muitos', a mais de uma singularidade, poderia designar a cruz do perdão?

É a poeta e jornalista sul-africana Antjie $\mathrm{Krog}^{14}$ (2004) que indica o párodo, a entrada da Comissão na sala de audiências: Desmond Tutu, seguido dos 17 comissários e comissárias, o canto do Hino Xhosa15, a vela acesa e a oração: "o perdão dos pecados devolve a integridade ao homem".

No burburinho babélico dos bastidores, os jornalistas querem saber mesmo é daqueles que vão pedir anistia, e se vem alguém importante. Krog (2004) nota a ausência de jornalistas negros e o fato de serem, em sua grande maioria, brancos, e homens. $\mathrm{O}$ que mais diferencia os estrangeiros, dirá depois, é o uso de perfumes e os equipamentos. Alguns se perguntam como fazer a reportagem desembaraçandose do próprio passado: "Quando eu estava no exército mandaram-me cortar os cabos da Radio Freedom... Isso me desqualifica ou não?". Será que as línguas oficiais dispõem das palavras necessárias para relatar o que vai se passar na comissão? Um intérprete do zulu se exalta. "Se não há palavras, inventamos". E começa a listá-las: um massacre: isibbicongo - crushed down; um serial killer: umbulali onequngu - addicted killer; uma emboscada: lalela unyendale - lying down waiting to do an evil act (p. 18-19).

Quem foi você durante o Apartbeid? É a pergunta que precisa ter uma verdade como resposta. Para Antjie Krog, o que há de original nesse trabalho da Comissão é justamente essa aposta na força retórica, na força performativa das narrativas, e em

14. Sigo de perto o testemunho de Antjie Krog, no livro Country ofmy Skull, na versão em francês La dou leur desmots (cf. referências).

15. O Hino Nkosi sikelel' iAfrika (The call of South Africa) foi composto em 1897 e adotado cem anos depois. É escrito/cantado em 5 línguas: xhosa, zulu, sesotho, africâner e inglês. 
certa capacidade terapêutica do discurso. E o que é preciso na cena da Comissão? É preciso dizer a verdade, toda a verdade, a todos: aos intérpretes (eis uma questão: de que forma o intérprete testemunha?), aos membros da comissão, a uma plateia de familiares, amigos, profissionais da imprensa, passando por todos os lugares de retransmissão do país. "Uma comissão pode ser sensível à palavra verdade?" Krog se pergunta. Ouçamos a sua resposta:

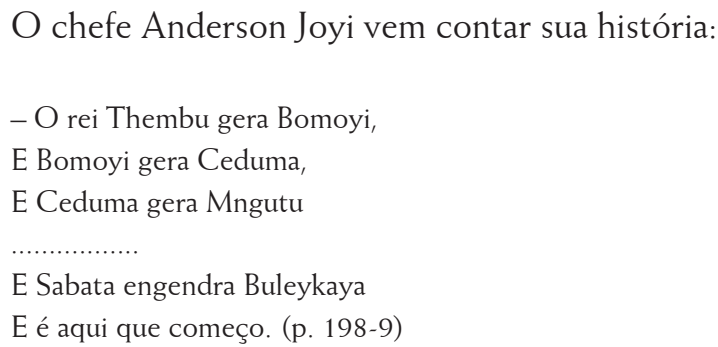

O chefe Anderson Joyi vem contar sua história:

- O rei Thembu gera Bomoyi,

E Bomoyi gera Ceduma,

E Ceduma gera Mngutu

E Sabata engendra Buleykaya

E é aqui que começo. (p. 198-9)

Se o seu interesse pela verdade está ligado unicamente à anistia e às indenizações, a opção será pela justiça e não pela verdade. Se ela [a Comissão] considera a verdade a mais vasta compilação de percepções, histórias, mitos e experiências, ela escolherá restaurar a memória e favorecer uma nova humanidade, e talvez esteja aí a justiça, no fundo de sua alma. (p. 21)

Os intérpretes reclamam que ele fala um xhosa muito antigo; que teriam que mergulhar no inglês medieval para dar conta da fala de Joyi. O que reconhecem na língua desse narrador é o que está além da memória do acontecimento narrado, e que ressoa, resistindo à tradução.

Antjie Krog pergunta por que ele enuncia a linhagem citando 18 gerações. O intérprete explica: "seus nomes determinam o fluxo do tempo. Seus nomes situam o que me aconteceu em um contexto. Seus nomes dizem que sou um chefe. Seus nomes dizem que nós somos capazes de suportar o passado... e o presente" (p. 199, itálicos acrescentados). O que o intérprete relata é justo o que do xhosa - do que lhe é singular, irredutível - se perde no inglês, e que remete, de imediato, à genealogia bíblica. Em seus estudos sobre os testemunhos na CVR, Fiona Ross (2003) reclama da forma como os relatos foram transcritos no relatório final: o estilo narrativo dos falantes de xhosa torna-se discurso indireto, é resumido, e dele se perdem as entonações, a postura corporal, as hesitações. O que para narradores de uma língua como o inglês é lido como "dar voltas antes de começar" pode ser o estilo daquela língua. Os contadores de histórias podem ser o pesadelo dos intérpretes.

William Matidza vem testemunhar. Krog conta que ele tem 100 anos (pelo que se lembra). Ele não vem testemunhar porque foi preso várias vezes por motivos 
políticos, mas porque tudo que tinha fora confiscado. "Mas não é a casa, os móveis, o gado - a essas perdas eu me adapto, mas, vejam, são as árvores..." ele quer uma reparação pelas árvores (p. 272-3).

Lebohang Matibela, um dos intérpretes citados nominalmente por Krog (2004, p. 298), descreve seu papel em termos teatrais e tenta falar disso:

na cabine do intérprete a gente não se dá conta de que se torna ator, e começa a se parecer com a vítima enquanto ela fala, e inconscientemente a gente levanta os braços quando ela faz isso... mas isso se torna muito difícil quando as pessoas se põem a chorar, e golfam palavras... dizem alguma coisa, ficam em silêncio, recomeçam... é preciso juntar todos os pedaços.

Não se envolvam! É o primeiro mandamento do intérprete. O intérprete tswana fala que é difícil traduzir o testemunho das vítimas, porque precisa falar em primeira pessoa e "não tenho como me distanciar quando digo o tempo todo... eu. O eu do outro me traspassa [...] O psicólogo me aconselhou a parar, você não deve se envolver - mas eu não posso, eu não quero, é a minha história, e faço parte dela até o fim" (KROG, 2004, p. 176).

$\mathrm{Na}$ obscura trama da verdade, o lugar reservado ao intérprete não se resume à ponte necessária. Entre o remain professional e a lealdade política à língua e à comunidade da testemunha, o intérprete está sempre dividido entre traduzir e testemunhar. O intérprete não escapa à contingência do que é ouvido, e que diz respeito ao que da voz da vítima e do torturador ele pode transmitir, e que está além da neutralidade ideal do intérprete, e que joga com sua (im)potência, e que vai além de qualquer domínio perfeito das línguas que traduz. Quando ele fala, engaja-se mais do que pensa, engaja seu corpo, e sua fala se faz também espetáculo.As cenas de tradução no palco da Comissão iluminam de forma quase brechtiana a questão da mediação.

Além de a tradução ser simultânea, muitas vezes acontece de o intérprete não estar sempre certo quanto ao idioma da pessoa que vem contar sua história (a vítima), ou depor (o perpetrador). Algumas vezes, a tradução passa de uma língua africana para o inglês e precisa ser ainda traduzido para o africâner. Além disso, todos os intérpretes precisam estar sempre disponíveis, uma vez que a Comissão é itinerante, e as línguas variam de região a região ${ }^{16}$.

"A tarefa primordial da Comissão - leio agora o relatório oficial - é considerar as consequências morais, políticas e legais do apartheid" (Volume V, 6 /65). Não

16. Merece registro o fato de que os textos transcritos das audiências não indicam o idioma utilizado nos relatos e depoimentos, exceto quando há algum problema de interpretação ou com o equipamento. Cf. TRC Report(1998). 
se trata de uma justiça que tem por fim a aplicação da lei penal, mas de uma justiça restauradora. Acertar as contas com a verdade e promover a reconciliação. É o que deseja Mandela. Mas é preciso voltar a falar do caráter religioso que Desmond Tutu imprime à cena e do perdão cristão: a anistia se torna perdão e, como acentua Derrida (2004a, p. 149), "um perdão precedido de um testemunho acompanhado de arrependimento. A cristianização sub-reptícia...". Contudo, a adoção da Constituição e os trabalhos da Comissão visavam garantir as condições para ultrapassar as divisões e conflitos do passado recente daquele país, uma vez que, nas palavras de Antjie Krog, havia "uma necessidade de compreensão e não de vingança, uma necessidade de ubuntu e não de vitimização" (2004, p. 22).A Comissão é um lugar de fala e, principalmente, de escuta... A voz dos intérpretes não é uma voz desencarnada, ausente da cena. É nela mesma que questionam suas próprias identidades, as formas como absorveram a violência das narrativas.

O relato do pastor (p. 283-290) é o título de um capítulo do livro de Krog. O pastor Lekotse ${ }^{17}$ começa a contar sua história. Lendo-a, é possível dizer que ele não vai direto ao ponto, mas, qual seria o ponto? Ele conta daquele dia, de sua mulher doente... O comissário tenta impor uma lógica, conduzir o relato. Pede-lhe que fale dos filhos. Ele volta ao dia do ataque, fala dos 10 filhos, ele está cansado, um dos filhos é doente mental, ... O comissário pede-lhe que fale do que aconteceu em maio de 1983 .

-Talvez o senhor tenha razão - veja meu problema.

É que eu era um pastor. Eu não sei ler. E eu esqueço todos esses dias, mas... Posso repetir o que eu disse antes sobre o cansaço? Agora, escute com atenção. Vou contar a história no presente.

Esse dia na vida de Lekotse não se marca no calendário da Comissão. O que importa mais? A data precisa?

-Naquele dia lá, era noite. Uma pessoa chegou e esmurrou a porta. Quando respondi a porta se abriu e eu perguntei: Quem bate assim tão forte? E ele respondeu: É a polícia. Ele forçou a passagem e derrubou a porta....abriram todas as portas da casa...

-Eu disse: quando um chacal ataca um carneiro ele não age assim... Por favor... Eles não responderam... Como ousam forçar as portas? Falei para meus filhos: preparem um chá, preparem um café para essa gente...,

17. A transcrição do relato de Joahnes Likotsi em Ladybrand. TRC Hearings, vol. 2, p. 1-80. No livro de Antjie Krog o nome é grafado Lekotse http://www.justice.gov.za/trc/hrvtrans/ladyb/ ladyb2.htm 
O comissário pergunta pelos ferimentos; pergunta se ele havia procurado a polícia.

- Como reclamar dos policiais para os policiais? Eles atacariam de novo. Foi por isso que eu lhe disse: "Mate todos nós para não ter mais problemas depois. É bem melhor morrer." E teria sido mesmo fácil nos enterrar numa única tumba.

O relato continua e volta sempre à porta derrubada, e a tudo o que caiu com ela. Importa destacar neste ponto que a questão, nessa obra de Antjie Krog, não é determinar se a forma e a estética podem traduzir, testemunhar o horror das atrocidades do apartheid - mesmo que seja essa uma questão que se reveste de importância para uma poeta com sete volumes de poesias publicados. O que subjaz a essa obra modelada no contexto da Comissão é sua tentativa de criar um espaço para nele traduzir as narrativas que foram silenciadas, ao mesmo tempo em que pede para ser ouvida. E a questão que escuto atravessar todo o seu livro parece ser: como trasladar para seu texto, ele mesmo um testemunho, o testemunho dos outros? Como cavar em suas letras o espaço adequado ao enxerto dessas narrativas? Haveria uma justa adequação?

\section{O CORPO DAS MULHERES COMO CAMPO DE BATALHA}

Toda ferida, mesmo psíquica, deixa uma cicatriz, e só o que deixa marca pode ser curado... Ouvimos ainda a voz de Jacques Derrida. E no seminário que lemos ele escreve: "a violação não é uma violência entre outras". E não porque, continua, frequentemente as testemunhas são mulheres, "mas porque a cena do testemunho e da verdade, da revelação da verdade, põe em cena o corpo da testemunha que pode ser também uma vítima (por exemplo, uma mulher vítima de tortura ou de violação)" (2004a, p. 143).

O corpo das mulheres como campo de batalha é o capítulo 13 do livro de Antjie, e começa com uma pergunta: "A verdade é feminina?" Os relatos das mulheres são marcados pela dor. A resposta à questão "o que é uma violação?" (p. 258) não é simples, observa a autora, a convenção de Genebra considera a violação um crime de guerra, mas pedir que não se anistiem os estupradores vai excluir qualquer possibilidade de confissão.

Os trabalhos da Comissão inscrevem-se no próprio processo político que instituem. Nesse processo, os holofotes produzem zonas de sombra e o burburinho das mídias silencia vozes. É esse o caso, por exemplo, do tratamento 
dado às mulheres, da atenção seletiva da mídia para as vítimas que valiam a pena. Anthonissen (2009, p. 101) fala sobre o sentimento de que os relatos das vítimas eram muitas vezes tomados como objetos de estudo, deixando nelas a sensação de terem sido abandonadas, uma vez 'vazias' de suas histórias. Para alguns, continua, a história não teve efeito terapêutico, e havia ainda o preconceito com relação a relatos muito hesitantes, que geravam dúvidas com relação à verdade do que dizia a testemunha (p. 104).

Para Lætitia Bucaille (2007, p. 316), falar pode ser de início um alívio, mas pode reabrir feridas. Além disso, o tratamento marcado de compaixão investe as testemunhas no papel de vítimas e o dever de assistência acaba por acentuar mais o sofrimento que a coragem. A promoção dessa categoria binária, torturador-vítima altera, segundo a autora, "o sentido político da luta das militantes [...] que correm o risco de se tornarem prisioneiras de uma identidade vitimada e, consequentemente, privada dos frutos de sua própria vitória" (p. 317).

No caso das mulheres há ainda o embaraço causado pelas diferenças culturais. Antjie Krog é sensível a essas questões, e a leitura de seu texto se torna difícil... No final desse capítulo ela reproduz o comentário de um fazendeiro: "não suporto mais ver esses choros na Comissão [...] os comportamentos mais desprezíveis, a covardia, a perda do controle de si" (p. 269). A Comissão reforça os estereótipos. Reforça o estranhamento do outro.

A intérprete Angela Sobey explica em entrevista a Yvette Hardie (2006) que não era qualificada para interpretar para a língua xhosa. Ela é coloured, não é negra, e precisa ser autorizada por Tutu, que conhecia seu trabalho de intérprete. Fala das dificuldades enfrentadas como tradutora, das críticas às roupas coloridas, ao uso de palavras que uma mulher não diria. Com relação à sua tarefa de tradutora, fala dos momentos de decisão - com uma escolha you make or break the story, e ficava então dividida entre favorecer a testemunha ou os ouvintes (p. 104). Khetiwe Marais, filha de nômades, fala as 11 línguas oficiais. Conta a Hardie que havia sido detida duas vezes, mas diz que seus problemas foram minúsculos perto do que ouviu na Comissão - e é crítica quanto ao que poderia ter sido feito, com relação aos "privilégios dados aos perpetradores". A tradução do perdão deixa restos na passagem entre as línguas: ela explica que tshwarelo é uma palavra sotho que significa perdão (forgiveness), mas, traduzida literalmente, tem a conotação de "cuide disso para mim" [hold this for me]. "A questão é que nessa língua, se estou pedindo perdão, preciso dar de volta aquilo que eu tomei" (p. 105). 


\section{VERDADE EM TRADUÇÃO- O CAIR DO PANO}

Onde quer que o 'nós' seja uma comunidade fusional... tenho uma espécie de alergia a uma comunidade desse tipo. Em contrapartida, eu chamaria de aceitável um nós feito de interrupções ... aquele que diz nós sabe que são singularidades que entram em uma relação interrompida... e a condição para que nos falemos é que essa interrupção da relação permaneça [D’Ailleurs, Derrida - última cena]

Antjie Krog chega à última audiência das vítimas. A mulher, afinal, "nunca chegou a reverter o estereótipo da Comissão: as mulheres são as vítimas; os homens, os combatentes, os chefes". Agora, os homens vão se ocupar da "Grande Política". Reparação e reconciliação são "coisas de mulheres" (p. 320). Para a poeta sulafricana, as pequenas luzes vermelhas dos microfones da Comissão são os últimos símbolos do processo: "era por lá que a voz dos marginalizados passava para a orelha do público; que se dizia - e se traduzia - o indizível; as histórias pessoais vindas das profundezas de cada indivíduo reconectam-se na história coletiva" (p. 321).

Como fazer coisas com palavras. How to do things with words. No caso da África do Sul, fazer uma história, um passado comum que permita uma convivência, que permita contestar as já naturalizadas alegações de supremacia cultural. Uma história feita de narrativas marginais, fragmentadas, que desafiam a história oficial e interrompem os nós fusionais.

Para que um espaço democrático se abra é preciso que em cada um, cidadão ou cidadã, essa multiplicidade de vozes seja, tanto quanto possível, liberada ...que cada cidadão e cidadã trate bem esse dentro, esse problema das vozes, da diferença sexual, dos fantasmas, para tratá-los bem fora. Se sou tirânico dentro de mim, tenderei a sê-lo fora. Com a política também é assim, como uma espécie de autoanálise, como uma espécie de experiência de si. [Derrida sai da cena]

As narrativas das vítimas e dos torturadores interpretadas para todas as línguas oficiais escreveram a possibilidade de restaurar o ubuntu. Em língua xhosa, o ubuntu é o que preserva a estabilidade do grupo. É o espírito de solidariedade. Uma filosofia africana. Somos, logo sou (o Cogito africano, na leitura de Krog). Só posso ser uma pessoa com outras. É por tudo isso que se fala em restaurar o ubuntu que a legislação do homem branco, o apartheid, tornou impossível.

[...] (iii) A "person of colour" designates a person which is neither white nor native. [...] (x) A "native" designates a person which is in fact or commonly considered to be from one of the aboriginal races or tribes of Africa. [...] (xv) A "white person" designates a person which is evidently such or commonly accepted as a white person, with the exclusion of any person, even in appearance being evidently white, commonly accepted as a person of colour. ${ }^{18}$

18. Trata-se do Population Registration Act 30 de 1950, citado por Salazar (1998, p. 27), falando do trabalho do legislador como um nomóteta, legislador, formador de nomes (que determina se são verdadeiros ou falsos). 


\section{PERDOA ESTA CANÇÃO IMPROVISADA - A HOMENAGEM DO POETA}

No final de seu livro sobre a dor das palavras, Antjie Krog fala do comitê de Reparações e de sua ajuda às famílias na realização do trabalho de luto. Em seu balanço, revela-se que a maior parte dos brancos tentou se eximir do apartheid rejeitavam o princípio da reparação e eram contra a política de ações afirmativas que davam prioridade às comunidades desfavorecidas sob esse regime.Estranha a palavra reconciliação: "neste país não existe ordem anterior que desejaríamos restaurar. Nestas circunstâncias difíceis, a palavra "conciliação" parece mais apropriada que "reconciliação" (p. 151). Conversando com o filósofo ativista chileno José Zalaquett, Krog escuta-o falar da diferença entre o processo de Nuremberg e os trabalhos das Comissões da Verdade. Para o chileno, a derrota dos alemães fora completa, e eles haviam perdido seu poder e seus fuzis, enquanto na África do Sul e no Chile, "o regime derrotado faz parte do novo governo e dispõe de um poder suficiente para torpedear os inquéritos, e talvez começar uma nova guerra civil". Em alguns momentos, Zalaquett continua, "é preciso escolher entre a verdade e a justiça. Devemos escolher a verdade. A verdade não traz de volta os mortos, mas liberta-os do silêncio" (p. 44).

Contra o esquecimento, restam as mareas os marcos. Na África do Sul foram construídos vários monumentos ${ }^{19}$. Persiste, no entanto, em cada um, a busca desse "local de testemunho". Para Márcio Seligmann-Silva (2008), esse local é "uma errância", um abrir-se para "suas fraturas e silêncios", e é "na literatura e nas artes" que essas vozes poderiam "ter melhor acolhida" (p. 78). Foi esse local errante que me levou a perguntar quem seriam então, hoje, os trovadores da verdade, da diferença, da diffèrance.

Samuel Lelièvre (2004) defende o que chama de memória viva, em canções, peças, filmes, que podem ter um valor mais presente que os monumentos e museus, necessariamente grandiosos. Cita então os filmes La commission de la vérité, de André Van In (1999); Long Night's Journey into Day, de Frances Reid e Deborah Hoffman (2000), e considera que "o filme documentário constitui também, para os sulafricanos, um modo de reapropriação de uma cidadania que, em escala nacional, permanece ainda a construir" (p. 439).

19. O Museu da África do Sul, em Johannesburgo; o SlaveLodgeMuseum e o Distrit Six Museum, na Cidade do Cabo; o Monumento e Museu Hector Pieterson, no Soweto (Johannesburgo); o Guguletbu Seven, Memorial na Cidade do Cabo, entre outros. 
Truth in translation é uma dessas memórias. Esse musical dirigido por Michael Lessac, com composições do Sul-africano Hugh Masekela, conta a história testemunhada pelos intérpretes, que atrizes e atores encenam em outros palcos. Os intérpretes foram as vozes das vítimas e dos torturadores, traduzindo seus testemunhos enquanto a Comissão lidava com a verdade - ora com a verdade fatual dos que pediram a anistia, ora com a verdade pessoal das narrativas das vítimas, uma a uma, tentando a partir delas construir um consenso, um passado. Levado aos palcos das cidades de Kigali (Rwanda), Belfast (Irlanda do Norte), Washington (EUA), Edimburgo (Escócia), Estocolmo (Suécia), Johannesburgo e Cidade do Cabo (África do Sul), além de Sarajevo e da Mostar Bridge (Bósnia), Pristina (Kosovo) e Zagreb (Croácia), a peça é uma nova forma de contar, cantar e decantar essa matéria feita de palavras.

Deixemos, portanto, às línguas e a seus poetas, a ocasião oportuna ao 'local da diferença'. Em Notas para uma concha (1980, p. 74), Francis Ponge fala dos enormes monumentos produzidos pela humanidade: pirâmides, catedrais, templos, estátuas, todos em desarmonia com o homem.Para o artista, o monumento de músicos e escritores da dimensão de Bach, Rameau, Malherbe, Horácio e Mallarmé "é feito da verdadeira secreção comum do molusco homem, da coisa mais proporcionada e condicionada ao seu corpo e, no entanto, a mais diferente de sua forma que se pode conceber, isto é, a PALAVRA".

\section{REFERÊNCIAS BIBLIOGRÁFICAS}

ANTHONISSEN, Christine. (2009). Considering the violence of voicelessness: censorship and self-censorship related do the South African process. In: WODAK, Ruth; BOREA, Gertraud Auer (eds.). Justice and memory confronting traumating pasts. International comparison.Viena: PassagenVerlag, pp. 97-122.

. (2008). On interpreting the interpreter - experiences of language practitioners mediating for TRC. Journal of Multicultural Discourses 3(3): 165-188.

AUSTIN, John Langshaw. (1970). A plea for excuses. In: AUSTIN, J. L. Philosophical papers. 2.ed. Oxford: Oxford University Press, pp. 175-204. . (1975). How to do things with words. 2. ed. Cambridge: Harvard University Press.

BUCAILLE, Lætitia. (2007). Vérité et réconciliation en Afrique du Sud: une mutation politique et sociale. Politique étrangère, IFRI, vol 2, pp. 313-325.

CASSIN, Barbara. (2004a). Amnistie et pardon: pour une ligne de partage entre éthique et politique. In: CASSIN, B.; CAYLA, O.; SALAZAR, Ph.-J. (dir.)Vérité, reconciliation, reparation.Paris: Seuil, v. 43, pp. 37-57. 
. (2004b). Présentation.In: CASSIN, B.; CAYLA, O.; SALAZAR, Ph.-J. (dir.)Vérité, reconciliation, reparation. Paris: Seuil, v. 43, pp. 13-26.

. (Dir.) (2004c). Vocabulaire Européen des Pbilosophes - dictionnaire des intraduisibles.Paris: Le Robert - Seuil.

D’AILLEURS, DERRIDA. (1999). Safaa Fathy (dir.), Jacques Derrida, Jean-Luc Nancy. La Sept Arte. Gloria Films Production. DVD. 68m.

DERRIDA, Jacques. (2004a). Versöbnung, ubuntu, pardon: quel genre? In: CASSIN, B.; CAYLA, O.; SALAZAR, Ph.-J. (dir.) Vérité, reconciliation, reparation.revue semestrielle Le genre bumain. Paris: Seuil, v. 43, pp. 111-156.

. (2004b). Pardonner: l'impardonnable et l'imprescritible. Cabier L'Herne, Jacdues Derrida, Paris: Éditions de l'Herne, pp. 541-560.

. (2004c). Poétique et politique dut émoignage. Cabier L'Herne, Jacques Derrida, Paris: Éditions de l'Herne, pp. 521-539.

FELMAN, S.; LAUB, D. (1992).Testimony: crises in witnessing in Literature, Psychoanalysis, and History. Nova York, Londres: Routledge.

GAGNEBIN, Jeanne Marie. (2006). Lembrar, escrever, esquecer. São Paulo: Editora 34.

HARDIE, Yvette. (2006).Invisible Angels. Entrevista com as intérpretes: Nomusa Zulu, Angela Sobey e Khetiwe Mboweni-Marais. Oprab's South Africa Magazine, pp. 102-105. Disponível em http://www.embreyfdn.org/embrey/OMagSAfricaArt.pdf Acesso em maio de 2011.

KROG, Antjie. (2004). La douleur des mots. Tradução de Georges Lory (do inglês Country of my skull: guilt, sorrow, and the limits of forgiveness in the New South Africa, 1998). Arles: Actes-Sud.

LELIÈVRE, Samuel. (2004). Afrique du Sud, apartheid et film documentaire. Cabiers d'Études africaines, XLIV (1-2), 173-174, pp. 435-439.

LOTRIET, Annelie. (2002). Can short interpreter training be effective? The South African Truth Reconciliation Comission experience. In: HUNG, Eva. Teaching translation and interpretation, vol 4. Philadelphia: John Benjamins, pp. 83-98.

. (2001). Sign Language Interpreting in South Africa: meeting the challenges. Critical Link, vol2. Disponível em http://criticallink.org/?s=lotriet Acesso em agosto de 2011.

MATHIBELA, Lebohang. (2007)Translation and the midia: translation and interpretation. In: VILLA-VICENCIO, Charles; DU TOIT, Fanie (eds.). Truth \& reconciliation in South Africa: 10 years on. África do Sul: New Africa Books.

PONGE, Francis. (1980). Notes pour un coquillage. Le Partipris des choses. Paris: Gallimard, coll. Poésie.

ROSS, Fiona. (2003). Bearing witness: women and the Truth and Reconciliation Commission in South Africa. Londres: Pluto Press.

SALAZAR, Philippe-Joseph.(2004). Une conversion politique du religieux. In: CASSIN, B.; CAYLA, O.; SALAZAR, Ph.-J. (dir.) Vérité, reconciliation, reparation.Paris: Seuil, pp. $37-57$. 
. (1998). Afrique du Sud, La révolution fraternelle. Paris: Hermann (coll. Savoirs: Cultures).

SELIGMANN-SILVA, Márcio. (2008). Narrar o trauma: a questão dos testemunhos de catástrofes históricas. Psicologia clínica. [online]. vol.20, n.1, pp. 65-82. Disponível em http://www.scielo.br/pdf/pc/v20n1/05.pdf Acesso em março de 2010.

SOOKA, Yasmin. (2004). Les victimes de l'apartheid prises dans la promesse d'amnistie. Traduzido do inglês por Barbara Cassin. In: CASSIN, B.; CAYLA, O.; SALAZAR, Ph.-J. (dir.) Vérité, reconciliation, reparation. Paris: Seuil, pp. 339-345.

THE SOUTH AFRICA TRUTH AND RECONCILIATION COMISSION (TRC). (1998). Report. Disponível em http://www.doj.gov.za/trc Acesso em agosto de 2008.

TRUTH IN TRANSLATION. Disponível em http://www.truthintranslation.org/index. $\mathrm{php} / \mathrm{v} 2 /$ Acesso em setembro de 2008.

TUTU, Desmond. (2000). No future without forgiveness. New York: First Image Books Edition.

Recebido: 26/10/2011

Aceito: 04/11/2011 